\title{
DIFFERENT CORTICOSTEROID THERAPY REGIMENS FOR NEPHROTIC SYNDROME IN CHILDREN
}

\author{
A.M. Sharipov, K.A. Khamzayev, B.B. Mamatkulov, Z.S. Umarova \\ Pediatric Nephrology, Tashkent Pediatric Medical Institute, Tashkent, Uzbekistan
}

Objective: To develop better therapy mode and reduce the rate of relapse of nephrotic syndrome in children with steroid sensitive nephrotic syndrome (SSNS).

Methods: Compared the effect of 2-month steroid treatment (standard course) according to International Study of Kidney Disease of Children (ISKDC) versus 6-month treatment (long course) on the clinical course of SSNS in a 2-year follow up in our centre. Long course of consisted from following: Prednisolone 60 $\mathrm{mg} / \mathrm{m} 2 /$ day for 4 weeks, then $40 \mathrm{mg} / \mathrm{m} 2 /$ alternate day for 4 weeks and slowly tapering off by $10 \mathrm{mg} / \mathrm{m} 2 /$ alternate day in four months, total course of 6 months.

Medical records of patients seen from 2008-2010 were reviewed. A total of 56 patients were included in the study (standard course group $=29$, long course group=27). All patients were treated with steroid alone. We have excluded patients who were previously treated, those who suffered from steroid resistant nephritic syndrome.

Results: After following up for 2 years, the relapse rates of both groups were

observed. Patients treated with long course steroid had significantly lower relapse rate $(33 \%$ versus $75 \%$, $\mathrm{p}=$ $0.026)$ and higher percentage of sustained remission $(\mathrm{p}=0.0046)$ than that of standard course. None of our patients had significant growth retardation or hypertension.

Conclusion: In conclusion, with the limitations and constraints in mind, the 6-month corticosteroid therapy is more likely to provide better rate of sustained remission when compared to the standard ISKDC regimen as the initial management of first episode SSNS. 